\section{Forced diuresis to reduce nephrotoxicity of streptozotocin in the treatment of advanced metastatic insulinoma}

Streptozotocin is a specific $\beta$ cell toxin that was first used to treat malignant islet cell tumours in 1968. ${ }^{1}$ Enthusiasm for its use, however, has been tempered by the high risk of nephrotoxicity, which occurs in up to $100 \%$ of patients. ${ }^{2}$ We report on the successful management of a patient with a malignant insulinoma who sustained renal impairment when treated with streptozotocin alone but tolerated repeated administration of the drug without deterioration in renal function when a hydration technique was used to administer the drug.

\section{Case report}

A 65 year old woman presented with a two year history of episodic abdominal pain, anorexia, and weight loss of about $19 \mathrm{~kg}$. A gall bladder calculus was visualised on abdominal ultrasound, and a secretin-pancreozymin test showed impaired bicarbonate secretion. At laparotomy there was a large, unresectable tumour of the body of the pancreas fixed to retroperitoneal structures with multiple hepatic, omental, and mesenteric metastases. Despite this she remained well for 18 months but then developed Whipple's triad of hypoglycaemic symptoms after fasting and exercise, relieved by glucose. She had inappropriately high insulin concentrations with a mean insulin to glucose ratio of $9 \cdot 2$, consistent with an insulin secreting tumour.

Streptozotocin $500 \mathrm{mg} / \mathrm{m}^{2}(700 \mathrm{mg})$ was infused on three occasions on alternate days. Her symptoms responded, but her renal function steadily deteriorated with a creatinine clearance of only $30 \mathrm{ml} / \mathrm{min}$ (figure) and mild proteinuria $(250 \mathrm{mg} / 24$ h); further treatment was therefore suspended. Her symptoms recurred one year later, at which stage her renal function had recovered. Based on our experience with another nephrotoxic drug, cisplatin, ${ }^{3}$ we tried administering streptozotocin accompanied by hydration and diuresis to minimise the renal damage.

We restarted streptozotocin at the same dose, but on each occasion the patient was prehydrated intravenously with two litres of normal saline hourly for two hours, and frusemide $40 \mathrm{mg}$ was also given intravenously 30 minutes after the infusion was started. When a good diuresis was established streptozotocin was then given by a second infusion over 60 minutes and the saline infusion was titrated to maintain a total urine output of four to five litres throughout the procedure, which lasted roughly four hours. To date this method has been successfully used for eight treatment schedules, and her renal function has remained stable with a creatinine clearance of about $60 \mathrm{ml} / \mathrm{min}$ and normal findings on urine analysis (figure).

\section{Comment}

Ninety percent of patients with malignant islet cell tumours have hepatic metastases at the time of diagnosis, so surgical treatment is usually

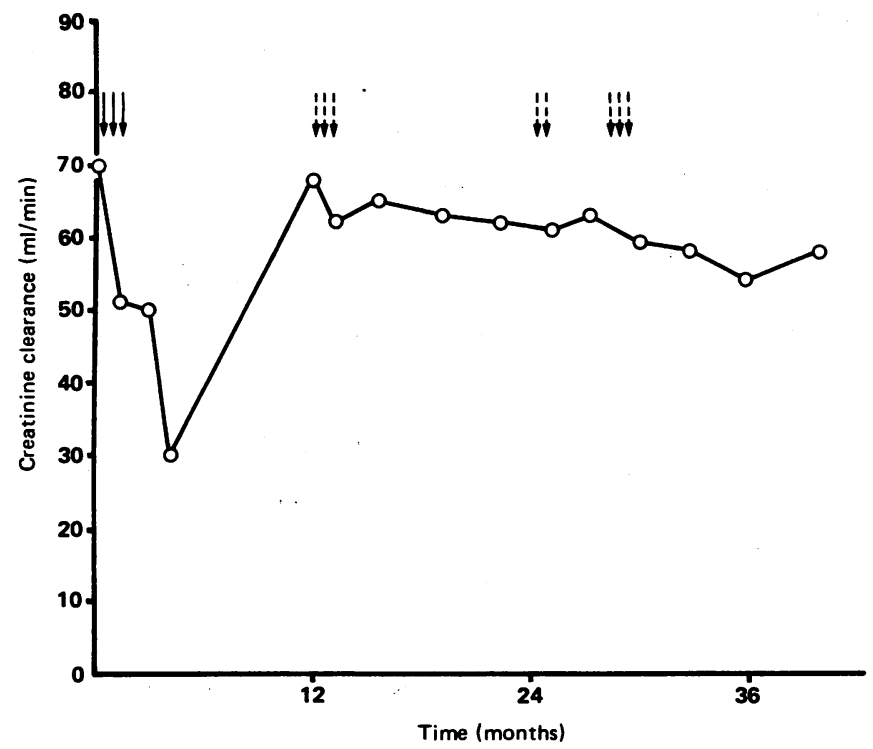

Creatinine clearance in relation to treatment with streptozotocin $\left(500 \mathrm{mg} / \mathrm{m}^{2}\right)$. Broken arrows represent administration using hydration technique. impracticable. Maintaining a high calorie intake or using diazoxide or long acting somatostatin analogue will help prevent the distressing hypoglycaemia secondary to hyperinsulinaemia but will not affect tumour growth. Since streptozotocin is the only specific agent currently available to treat advanced metastatic islet cell tumours, ${ }^{45}$ its renal toxicity is a major drawback. ${ }^{2}$ Using the hydration technique in our patient allowed continued use of streptozotocin without further renal damage and with no indication that its therapeutic efficacy was compromised since the patient remained symptomatically well with a mean insulin to glucose ratio of 5.0 throughout the period.

This experience suggests that the nephrotoxicity of streptozotocin can be mitigated by inducing a forced diuresis, a technique we therefore recommend as definitive treatment for an advanced malignant insulinoma.

1 Murray-Lyon IM, Eddleston AL, Williams R, et al. Treatment of multiple-hormone-producing malignant islet cell tumour with streptozotocin. Lancet 1968;ii:895-8.

2 Sadoff L. Nephrotoxicity of streptozotocin. Cancer Chemother Rep 1970;54:457-9.

3 Hayes DM, Cvitkovic E, Golbey $R$, et al. High dose cis-platinum diammine dichloride. Amelioration of renal toxicity by mannitol diuresis. Cancer 1977;39:1372-81.

4 Carter SK, Broder L, Friedman M. Streptozotocin and metastatic insulinoma. Ann Intern Med 1971;74:445-6.

5 Broder LE, Carter SK. Pancreatic islet cell carcinoma. Ann Intern Med 1973;79:108-18.

(Accepted 9 February 1987)

Gastroenterology Unit, Royal Liverpool Hospital, Liverpool L7 8XP

M V TOBIN, MB, MRCP, registrar in gastroenterology

H M WARENIUS, MRCP, FRCR, professor of radiation and oncology A I MORRIS, MD, FRCP, consultant physician and gastroenterologist

Correspondence to: Dr Tobin, Department of Medicine, University of Manchester, Hope Hospital, Salford M6 8HD.

\section{Simple thyroid cyst: cause of acute bilateral recurrent laryngeal nerve palsy}

Upper airway obstruction due to goitre usually results from tracheal compression or invasion. Anaplastic carcinoma, lymphoma, and retrosternal goitre are the common causes. These may also compress or invade the recurrent laryngeal nerves, causing airways obstruction from vocal cord paralysis. We report a case of acute upper airway obstruction secondary to bilateral recurrent laryngeal nerve compression by a simple thyroid cyst.

\section{Case report}

A 40 year old nursing auxiliary was admitted after collapsing in acute respiratory distress. She had a four week history of a steadily enlarging goitre. Four days before admission this had begun to enlarge rapidly, accompanied by hoarseness, stridor, and progressive dyspnoea. She had considerable inspiratory stridor with minimal respiratory distress in the sitting position but could not recline without precipitating acute dyspnoea. There was a smooth, non-tender $3 \times 4 \mathrm{~cm}$ swelling limited to the lower pole of the left lobe of the thyroid gland.

The results of her thyroid function tests were normal. A chest $x$ ray film and thoracic inlet views showed no evidence of tracheal compression. A laryngologist performed indirect laryngoscopy. This showed complete paralysis of the left vocal cord, which occupied the paramedian position, and paresis of the right cord, which was lying in the semi-adducted position with limited abduction and adduction. She was treated overnight with intranasal oxygen and slept sitting in bed. At operation the next morning a cyst of the left lower pole of the thyroid was identified. The cyst fluid was translucent and not bloodstained, the rest of the thyroid gland being normal. Frozen section examination of the wall of the cyst showed no evidence of malignancy and a left hemithyroidectomy was performed. Complete visualisation of the left recurrent nerve along its course in the neck showed no abnormality.

The patient had complete relief of stridor and respiratory distress immediately after operation, and at extubation both vocal cords were seen to abduct. A check laryngoscopy three days later showed normal position and movement of the vocal cords. Paraffin section histology of the left lobe of the thyroid showed the changes of a nodular colloid goitre with a cyst cavity $3 \mathrm{~cm}$ in diameter.

\section{Comment}

Upper airway obstruction due to bilateral recurrent laryngeal nerve palsy usually results from total thyroidectomy or an anaplastic carcinoma of the 
thyroid. ${ }^{1}$ It is rare for benign goitre to cause paralysis of the cord. ${ }^{2}$ In the only previous case report of a thyroid cyst causing unilateral recurrent nerve palsy the patient had a seven year history of hoarseness and goitre. ${ }^{3}$ Rapidly progressive bilateral recurrent laryngeal nerve palsy secondary to acute enlargement of a cyst has not been reported.

It is difficult to explain the rapid onset of bilateral nerve compression and the sudden relief of symptoms by operation. Rapid expansion of a cyst, with a sudden general increase in pressure within the confines of the pretracheal fascia sufficient to impair the microcirculation to both recurrent nerves, seems the most likely mechanism-in other words, a pretracheal compartment syndrome. The fact that this does not occur more often may relate to the great variability of this fascial layer and its relations with the recurrent laryngeal nerves. The nerves may be within the fascial compartment proper, invested by the fascial sheath itself, or completely outside the compartment for the whole of their course.

Percutaneous needle aspiration of such a cyst is likely to relieve the pressure on the recurrent nerves sufficiently to reduce dyspnoea and stridor before definitive surgery. This is proposed as the initial treatment when acute enlargement of the cyst or haemorrhage within it compromises the upper airway.

1 Lawson VG. The management of airway involvement in thyroid tumours. Arch Otolaryngol 1983;109:86-90.

2 Holl-Allen RTJ. Laryngeal nerve paralysis and benign thyroid disease. Arch Otolaryngol 1967;84:335-7.

3 MacLellan DG, Stephens DA. Recurrent laryngeal nerve paralysis: compression by a thyroid cyst. Med F A ust 1980;2:450.

4 Wade JSH. Vulnerability of recurrent laryngeal nerves at thyroidectomy. $\operatorname{Br} \mathcal{O}$ Surg 1955;43: 164-80.

(Accepted 5 February 1987)

\section{Selly Oak Hospital, Birmingham}

J S GANI, FRCS, surgical registrar

J M MORRISON, FRCS, consultant surgeon

Correspondence to: $\mathrm{Mr}$ J S Gani, Faculty of Surgical Sciences, David Maddison Building, King Street, Newcastle 2300, New South Wales, Australia.

\section{Remission of symptoms in carcinoid syndrome with a new 5-hydroxytryptamine $M$ receptor antagonist}

The principal features of the carcinoid syndrome are flushing and diarrhoea. The tumours often grow slowly, and disabling symptoms may continue for many years. Symptomatic treatment by pharmacological methods or debulking procedures can improve the quality of life of many patients, ${ }^{1}$ but the available drugs are often not completely effective. We report on the efficacy of a new drug, [1H]-indol-3-carbonic-acid-tripine-esterhydrochloride (ICS 205-930, Sandoz, Basle, Switzerland), ${ }^{2}$ one of the first generation of specific 5-hydroxytryptamine $M$ (neuronal) receptor antagonists. ${ }^{3}$

\section{Patients, methods, and results}

We studied three patients (cases 1-3) with secretory diarrhoea due to the carcinoid syndrome and two controls (cases 4 and 5) with similar secretory diarrhoea due to metastatic vasoactive intestinal peptide (VIP) secreting tumours. The first patient was a 72 year old man with a four year history of severe diarrhoea up to 19 times a day. He suffered only occasional flushes but profuse postprandial sweating. Medication was prednisolone $20 \mathrm{mg} /$ day, azothiaprine $150 \mathrm{mg} /$ day (bullous pemphigoid had been diagnosed two years earlier), and cyproheptadine $12 \mathrm{mg} /$ day. Case 2 was a 41 year old woman with an eight year history of carcinoid disease. She had watery diarrhoea up to 15 times a day and frequent flushing. Medication was cyproheptadine $12 \mathrm{mg} / \mathrm{day}$. Case 3 was a 54 year old man with a two year history of watery diarrhoea and infrequent flushing. Medication was methysergide $1 \mathrm{mg} /$ day. The controls (aged 46 and 50) both suffered secretory diarrhoea due to metastatic VIP secreting tumours. Both were receiving codeine phosphate and loperamide and case 5 was also treated with the somatostatin analogue SMS 201-995.

No changes were made to the subjects' long term medication. Stool collections were weighed daily for three days before the study and repeated while the subjects received a three day course of ICS 205-930 administered by slow intravenous injection. Serial 24 hour urinary 5-hydroxyindole acetic acid estimations were made throughout the period.

The diarrhoea improved considerably in the three patients with carcinoid syndrome but not in the controls (table). Flushing in the patients with carcinoid syndrome did not change, but sweating improved considerably in the one patien in whom it was troublesome (case 1). Urinary 5-hydroxyindole acetic acid excretion was unchanged in all subjects (table).

One of the five subjects (case 2) developed fever (peak temperature $39^{\circ} \mathrm{C}$ ) 36 hours after starting treatment, and the drug was stopped. She had suffered continuous diarrhoea for four years, and this symptom had resolved completely during this first day of treatment. Two months later rechallenge at a lower dose ( $20 \mathrm{mg}$ daily) on two days was again followed by a fever, strongly suggesting an idiosyncratic drug reaction. The four other subjects tolerated the drug well.

\section{Comment}

Peripheral 5-hydroxytryptamine receptors have been divided into two groups. ${ }^{4}$ The D receptors exist mainly on smooth muscle cells, and the $M$ receptors are primary neuronal, acting by modulating the release of other neurotransmitters. Several antagonists of the $D$ (smooth muscle) receptors (such as methysergide) have been developed, which either have proved poorly effective in the carcinoid syndrome or have unacceptable toxicity. The specific symptomatic response produced by ICS 205-930 in our three patients suggests that 5 -hydroxytryptamine $M$ receptors mediate the secretory diarrhoea of the carcinoid syndrome and may be partially implicated in the sweating. Diarrhoea in the carcinoid syndrome may also, of course, be due to bacterial overgrowth or bile salt spillage or develop as a postoperative complication, and specific therapies would be necessary in these circumstances.

This study suggests that 5-hydroxytryptamine $M$ receptor antagonist drugs will have an important role in the symptomatic treatment of watery diarrhoea in the carcinoid syndrome. The assessment of this new class of drug in other conditions in which 5-hydroxytryptamine overreactivity may be implicated is awaited with interest.

1 Graham-Smith DG. Natural history and diagnosis of the carcinoid syndrome. Clin Gastroenterol 1974;3:575-94

2 Donatsch P, Engel G, Richardson BP, Stadler PA. A highly selective and potent antagonist at peripheral neuronal S-hydroxy tryptamine receptors. Br $\mathcal{F}$ Pharmacol 1984;81:34P.

3 Richardson BP, Engel G, Donatsch P, Stadler PA. Identification of serotonin M-receptor sub-types and their specific blockade by a new class of drugs. Nature 1985;316:126-31.

4 Gaddum JH, Picarelli ZP. Two kinds of tryptamine receptors. Br Y Pharmacol 1957;12:323-8.

5 Welch JP, Malt RA. Management of carcinoid tumours of the gastrointestinal tract. Surg Gynecol Obstet 1977;145:223-7.

(Accepted 5 February 1987)

Department of Medicine, Royal Postgraduate Medical School, Hammersmith Hospital, London W12 OHS

J V ANDERSON, MB, MRCP, research fellow

$M$ O COUPE, MB, MRCP, registrar

J A MORRIS, MB, MRCP, senior house officer

H J F HODGSON, DM, FRCP, senior lecturer

S R BLOOM, MD, FRCP, professor of endocrinology

Correspondence to: Professor Bloom.

Details of symptoms and treatment in three patients with carcinoid syndrome and two with vipomas

\begin{tabular}{|c|c|c|c|c|c|c|c|}
\hline \multirow[b]{2}{*}{ Case No } & \multicolumn{2}{|c|}{$\begin{array}{l}\text { Mean stool weight } \\
(\mathrm{g} / \text { day })\end{array}$} & \multicolumn{2}{|c|}{$\begin{array}{l}\text { Mean stool frequency } \\
\text { (motions/day) }\end{array}$} & \multicolumn{2}{|c|}{$\begin{array}{c}\text { Mean urinary 5-hydroxyindole acetic acid } \\
(\mu \mathrm{mol} / 24 \mathrm{~h})\end{array}$} & \multirow{2}{*}{$\begin{array}{l}\text { Daily dose of ICS 201-950 } \\
\text { (mg on each day) }\end{array}$} \\
\hline & Before & During & Before & During & Before & During & \\
\hline
\end{tabular}

